\title{
Dual-energy spectral CT characteristics in surgically resected lung adenocarcinoma: comparison between Kirsten rat sarcoma viral oncogene mutations and epidermal growth factor receptor mutations
}

\author{
Meng Li ${ }^{1}$, Li Zhang ${ }^{1}$, Wei Tang ${ }^{1}$, Jian-Chun Duan ${ }^{2}$, Yu-Jing Jin ${ }^{1}$, Lin-Lin $Q i^{1}$ and Ning $W^{1}{ }^{1,3^{*}}$ (D)
}

\begin{abstract}
Background: Kirsten rat sarcoma viral oncogene homolog (KRAS) and epidermal growth factor receptor (EGFR) are the two most frequent and well-known oncogene of lung adenocarcinoma. The purpose of this study is to compare the characteristics measured with dual-energy spectral computed tomography (DESCT) in lung adenocarcinoma patients who have KRAS and EGFR gene mutations.

Methods: Patients with surgically resected lung adenocarcinoma $(n=72)$ were enrolled, including 12 patients with KRAS mutations and 60 patients with EGFR mutations. DESCT quantitative parameters, including the CT number at $70 \mathrm{keV}$, the slopes of the spectral attenuation curves (slope $\lambda \mathrm{HU}$ ), normalized iodine concentration (NIC), normalized water concentration (NWC), and effective atomic number (effective Z), were analyzed. A multiple logistic regression model was applied to discriminate clinical and DESCT characteristics between the types of mutations.

Results: The KRAS mutation was more common in people who smoked than the EGFR mutation. Nodule type differed significantly between the KRAS and EGFR groups $(P=0.035)$, and all KRAS mutation adenocarcinomas were solid nodules. Most DESCT quantitative parameters differed significantly between solid nodules and subsolid nodules. CT number at $70 \mathrm{keV}$, slope $\lambda \mathrm{HU}, \mathrm{NIC}$, and effective $Z$ differed significantly between the KRAS and EGFR groups $(P=0.006,0.017,0.013$ and 0.010$)$ with solid lung adenocarcinoma. Multivariate logistic analysis of DESCT and clinical features indicated that besides smoking history, the $C T$ value at $70 \mathrm{keV}(\mathrm{OR}=0.938, P=0.009)$ was significant independent factor that could be used to differentiate KRAS and EGFR mutations in solid lung adenocarcinoma.
\end{abstract}

Conclusions: DESCT would be a potential tool to differentiate lung adenocarcinoma patients with a KRAS mutation from those with an EGFR mutation.

Keywords: Dual-energy spectral computed tomography, Adenocarcinoma of lung, Solid nodule, Subsolid nodule, EGFR mutation, KRAS mutation

\footnotetext{
*Correspondence: cjr.wuning@vip.163.com

'Department of Diagnostic Radiology, National Cancer Center/National Clinical Research Center for Cancer/Cancer Hospital, Chinese Academy of Medical Sciences and Peking Union Medical College, Beijing, 100021, China ${ }^{3}$ PET-CT Center, National Cancer Center/National Clinical Research Center for Cancer/Cancer Hospital, Chinese Academy of Medical Sciences and Peking Union Medical College, Beijing, 100021, China

Full list of author information is available at the end of the article
}

(c) The Author(s). 2019 Open Access This article is distributed under the terms of the Creative Commons Attribution 4.0 International License (http://creativecommons.org/licenses/by/4.0/), which permits unrestricted use, distribution, and reproduction in any medium, provided you give appropriate credit to the original author(s) and the source, provide a link to the Creative Commons license, and indicate if changes were made. The Creative Commons Public Domain Dedication waiver (http://creativecommons.org/publicdomain/zero/1.0/) applies to the data made available in this article, unless otherwise stated. 


\section{Introduction}

Lung cancer is the leading cause of cancer deaths worldwide, and adenocarcinoma is its most common histologic form [1, 2]. Lung adenocarcinoma is considered a highly molecular heterogeneous disease [3]. In recent years, interest in the key role of proto-oncogenes in lung adenocarcinoma has been growing because of the rapid advances in molecularly targeted therapies. Kirsten rat sarcoma viral oncogene (KRAS) and epidermal growth factor receptor $(E G F R)$ are the most frequent and wellknown mutated oncogenes in adenocarcinoma of the lung. Compared with other types of lung adenocarcinoma, lung adenocarcinoma with EGFR mutation shows a good response to treatment with EGFR tyrosine kinase inhibitors (TKIs), such as gefitinib and erlotinib $[4,5]$. However, KRAS is still considered a nondrug target, and efforts to therapeutically target KRAS mutations have proved unsuccessful [6]. Indeed, KRAS has been proven to be a biomarker of resistance to EGFR-TKI treatment. In addition, previous studies have indicated that KRAS mutations are associated with worse survival, and these mutations are thought to be a negative prognostic marker in patients with lung cancer, especially patients with adenocarcinoma and early stage disease [7-11]. In the latest guideline (2018) from the College of American Pathologists/International Association for the Study of Lung Cancer/Association of Molecular Pathology, EGFR is indicated as a necessary testing gene for lung adenocarcinoma, and KRAS is a recommended testing gene, especially in cases where routine tests for EGFR show negative results [12].

Medical imaging - particularly computed tomography (CT) - is an essential noninvasive procedure for lung cancer diagnosis, staging and therapeutic response evaluation. The relationship between CT characteristics and lung cancer gene phenotypes has been a research area of particular interest, especially in relation to EGFR mutation [13, 14]. However, only a few studies have examined the correlation between the CT findings of lung adenocarcinoma and KRAS mutational status [15-18]. These studies showed that no or few inconsistent CT characteristics were associated with KRAS mutations. Furthermore, conventional $C T$ imaging signs lack quantitative evaluation, making them vulnerable to subjective judgment. As a new, revolutionary CT imaging method, dual-energy spectral CT (DESCT) can improve material differentiation by using two different X-ray energy spectra $[19,20]$. Compared to conventional mix-energy CT, DESCT scan can use a single tube with fast and dynamic $\mathrm{kVp}$ switching between 80 and $140 \mathrm{kVp} \mathrm{X-rays} \mathrm{during} \mathrm{a} \mathrm{single} \mathrm{rotation} \mathrm{and}$ generates 101 monochromatic CT images in the range of 40 to $140 \mathrm{keV}$, as well as iodine/water-based density and effective atomic number images [21, 22]. Therefore, DESCT can provide multiple quantitative measurements, including the monochromatic CT number, the slope of the spectral Hounsfield unit (HU) curve (slope $\lambda \mathrm{HU}$ ) based on monochromatic images, the iodine concentration (IC) based on iodine-based density images, the water concentration (WC) based on water-based density images, and the effective atomic number (effective $\mathrm{Z}$ ) based on effective atomic number images. It has been proven that DESCT has potential applications in various clinical areas, including diagnostics in oncology [20,23, 24]. Regarding lung cancer, DESCT has been employed in the differential diagnosis of cancers from benign lung nodules and the identification of lymph node metastases and has been used to distinguish histologic subtypes, such as adenocarcinoma and squamous cell carcinoma [25-31].

The occurrence of KRAS and EGFR mutations is mutually exclusive, and they exhibit many contrasting characteristics, such as clinical background and prognostic implications. To our knowledge, there has been scarce previous description of the DESCT characteristics of tumors with a KRAS mutation. We hypothesized that DESCT features can be used to distinguish KRAS mutations from EGFR mutations in lung adenocarcinoma. Therefore, we aimed to retrospectively explore potential differences in DESCT features between KRAS and EGFR mutations in a cohort of Chinese patients with lung adenocarcinomas.

\section{Materials and methods}

\section{Patient selection}

The study population was retrospectively selected from a prospectively collected and recorded database of information from patients who had lung nodules and masses and were undergoing pretreatment chest spectral DESCT from May 2013 to December 2015 at our institution. Inclusion criteria included being diagnosed with a cell type adenocarcinoma and having testing performed for EGFR and KRAS mutations after radical surgery at our institution (Fig. 1). The institutional ethics committee approved this study of prospectively collected data. Written informed consent for the use of clinical and imaging data for scientific and/or educational purposes was waived for this retrospective study.

\section{DESCT examination}

All patients received a DESCT (Discovery CT 750 HD, GE Healthcare, USA) enhanced chest scan from the apex of the lung to the adrenal gland before treatment. The scan applied gemstone spectral imaging (GSI) mode protocol, whose tube voltage fast switching between $80 \mathrm{keV}$ and $140 \mathrm{keV}$ with a cycle of $0.5 \mathrm{~ms}$. The other scanning parameters were as follows: tube current of $550 \mathrm{~mA}$, tube rotation time of $0.6 \mathrm{~s}$, collimator of $40 \mathrm{~mm}$, helical mode with a pitch of 0.984 , field of view (FOV) of large body, and slice thickness and interval for axial images of $1.25 \mathrm{~mm}$ and $0.8 \mathrm{~mm}$. All patients were intravenously injected with 


\section{Consecutive patients underwent chest DESCT scan from May}

2013 to December 2015 with pathological diagnosis $(n=1010)$
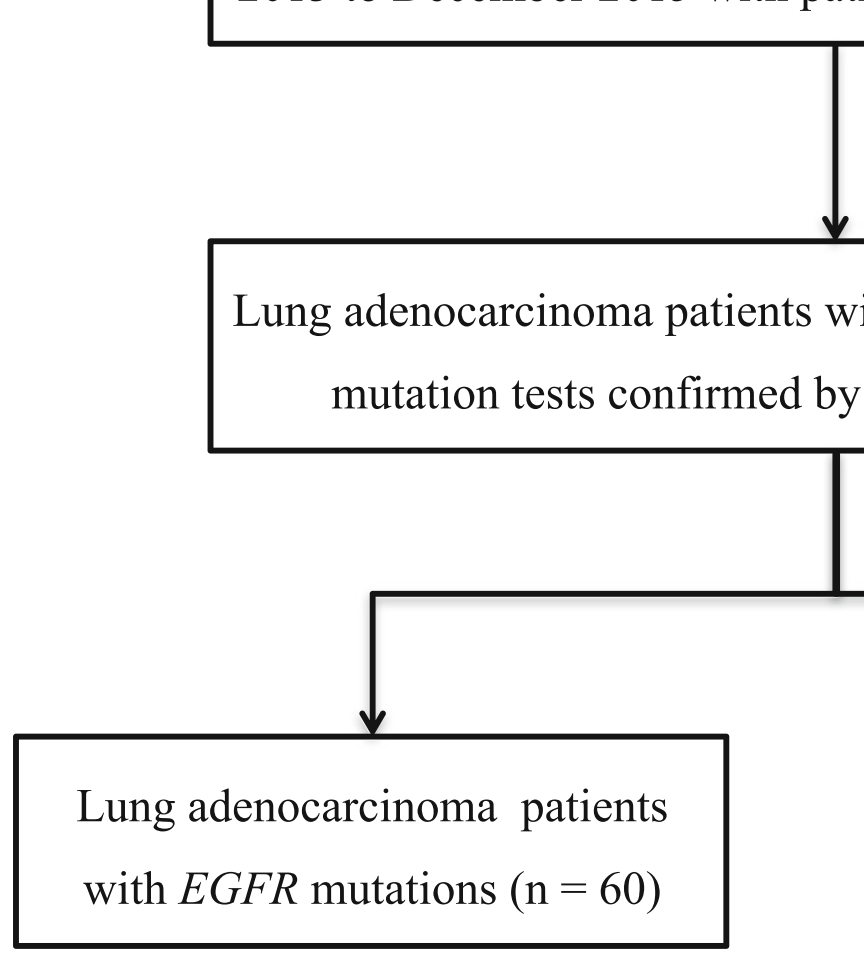

Fig. 1 Flowchart depicting the patient selection

contrast media (Ultravist 300; Bayer Pharma AG, Germany) using a power injector at a rate of $2.5 \mathrm{ml} / \mathrm{s}$ and volume of $85-100 \mathrm{ml}(1.5 \mathrm{ml} / \mathrm{kg}$ of body weight). The scan acquisition was started after a delay of $35 \mathrm{~s}$.

\section{DESCT image analysis}

The CT of all lung nodules was evaluated visually by two experienced radiologists. The morphological nodule type included solid nodule (SN), part-solid nodule (PSN) or mixed ground-glass opacity (GGO), and nonsolid nodule (NSN) or pure GGO; NSN was defined as a hazy increased opacity of lung, with preservation of bronchial and vascular margins; PSN was defined as a combination of ground glass and solid attenuation, which obscures the underlying lung architecture on CT; NSN and PSN were both referred to as subsolid nodules (SSN) [32-34].

The original data acquired were reconstructed into monochromatic images. The reconstructed images were sent to a post processing workstation (Advantage Workstation 4.6, GE Healthcare, Milwaukee, WI), where GSI Viewer software was used to analyze the enhanced monochromatic data and determine quantitative parameters. For the axial image, a radiologist with 10 years of experience in CT diagnosis of chest tumors selected the axial CT slice that depicted the maximum diameter of the primary tumor and positioned the region of interest (ROI) at the center of the lesion manually. The ROI range was drawn with no less than $2 / 3$ of the area of the lesion. Cavities, vacuoles, calcification, blood vessels and pulmonary atelectasis were avoided. Quantitative parameters measured included IC, WC, effective $\mathrm{Z}$ and slope $\lambda$ $\mathrm{HU}$, which was calculated as the difference between the CT number at $40 \mathrm{keV}$ and that at $100 \mathrm{keV}$ divided by the energy difference of $60 \mathrm{keV}$ [slope $\lambda \mathrm{HU}=(\mathrm{CT}$ number at $40 \mathrm{keV}-\mathrm{CT}$ number at $100 \mathrm{keV}) / 60]$. The enhanced $\mathrm{CT}$ number at $70 \mathrm{keV}$ was selected because the $120 \mathrm{kVp}$ scanning in conventional polychromatic images has an average energy of approximately $70 \mathrm{keV}$ in the GSI mode. To minimize the variations caused by the patient's circulation status and the scanning times, the IC and WC of each lung lesion were normalized to the IC and WC of the descending aorta, respectively, at the T6 level to calculate a normalized IC $\left(\mathrm{NIC} ; \mathrm{NIC}=\mathrm{IC}_{\text {lesion }} /\right.$ $\left.\mathrm{IC}_{\text {aorta }}\right)$ and a normalized WC $\left(\mathrm{NWC} ; \mathrm{NWC}=\mathrm{WC}_{\text {lesion }} /\right.$ $\left.\mathrm{WC}_{\text {aorta }}\right)$. Finally, five types of quantitative data were obtained: CT number at $70 \mathrm{keV}$, slope $\lambda \mathrm{HU}, \mathrm{NIC}, \mathrm{NWC}$ and effective $\mathrm{Z}$. 
Table 1 Comparison between clinical and CT texture with KRAS and EGFR mutation status in lung adenocarcinoma

\begin{tabular}{|c|c|c|c|c|}
\hline Characteristics & Total & KRAS & EGFR & $P$ value \\
\hline No. of patients & 72 & 12 & 60 & \\
\hline Age $(y)^{a}$ & $56.75 \pm 10.13$ & $58.75 \pm 7.53$ & $56.35 \pm 10.58$ & 0.458 \\
\hline Sex & & & & 0.054 \\
\hline Female & $42(58.3)$ & $4(33.3)$ & $38(63.3)$ & \\
\hline Male & $30(41.7)$ & $8(66.7)$ & $22(36.7)$ & \\
\hline Smoking & & & & 0.002 \\
\hline Never smoked & $55(76.4)$ & $4(33.3)$ & $47(78.3)$ & \\
\hline Smoker & $17(23.6)$ & $8(66.7)$ & $13(21.7)$ & \\
\hline Location & & & & 0.521 \\
\hline Central & $2(2.8)$ & $0(0.0)$ & $2(3.3)$ & \\
\hline Peripheral & $70(97.2)$ & $12(100.0)$ & $58(96.7)$ & \\
\hline T stage & & & & 0.066 \\
\hline $\mathrm{T}_{1-2}$ & $68(94.4)$ & $10(83.3)$ & $58(96.7)$ & \\
\hline$T_{3-4}$ & $4(5.6)$ & $2(16.7)$ & $2(3.3)$ & \\
\hline N stage & & & & 0.702 \\
\hline $\mathrm{N}_{0}$ & $47(65.3)$ & $9(7.5)$ & $38(63.3)$ & \\
\hline $\mathrm{N}_{1-2}$ & $25(34.7)$ & $3(2.5)$ & $22(36.7)$ & \\
\hline Maximum diameter ${ }^{b}$ & $2.89 \pm 1.29$ & $3.17 \pm 1.38$ & $2.83 \pm 1.29$ & 0.666 \\
\hline $\mathrm{CT}$ texture feature & & & & 0.035 \\
\hline SN & $56(77.8)$ & $12(100.0)$ & $44(73.3)$ & \\
\hline SSN (PSN and NSN) & $16(22.2)$ & $0(0.0)$ & $16(26.7)$ & \\
\hline
\end{tabular}

Note. Values are mean \pm standard deviation or number (percentage)

${ }^{a}$ Quantitative data exhibited normal distribution and T test was applied

${ }^{\mathrm{b}}$ Quantitative data did not exhibit normal distribution and Mann-Whitney $U$ test was applied

$P<0.05$ indicates significant difference. Significant $P$ values are in bold

SN solid nodule, SSN Subsolid nodule, NIC Normalized iodine concentration, NWC Normalized water concentration, Slope $\lambda$ HU the slope of the spectral Hounsfield unit curve, Effective $Z$ effective atomic number

Tumor pathologic characteristics and mutation analysis All patient pathologies were confirmed by radical operative pathological examinations. All histologic and mutation analyses were performed on surgical specimens. Tumor histologic characteristics were classified on the basis of the 2015 World Health Organization criteria.
The mutation status of KRAS and EGFR was examined by molecular pathological analysis.

\section{Statistical analysis}

The patient clinical and DESCT characteristics of the study population are expressed as the means and standard

Table 2 Association of CT texture type and DESCT features

\begin{tabular}{lllll}
\hline Characteristics & Total & SN & SSN & P value \\
\hline No. of patients & 72 & 56 & & \\
DESCT quantitative parameter & & & $-189.49 \pm 209.28$ \\
$\quad$ CT number at $70 \mathrm{keV}^{\mathrm{a}}$ & $-5.25 \pm 139.64$ & $47.39 \pm 23.04$ & $2.78 \pm 0.98$ & $\mathbf{0 . 0 0 0}$ \\
Slope $\lambda \mathrm{HU}^{\mathrm{a}}$ & $1.95 \pm 1.03$ & $1.71 \pm 0.92$ & $0.28 \pm 0.11$ & $\mathbf{0 . 0 0 0}$ \\
NIC $^{\mathrm{a}}$ & $0.22 \pm 0.12$ & $0.19 \pm 0.12$ & $0.74 \pm 0.19$ & $\mathbf{0 . 0 0 4}$ \\
NWC $^{\text {a }}$ & $0.93 \pm 0.14$ & $0.99 \pm 0.02$ & $6.69 \pm 3.53$ & $\mathbf{0 . 0 0 0}$ \\
Effective Z & $8.06 \pm 1.82$ & $8.45 \pm 0.43$ & & 0.866 \\
\hline
\end{tabular}

Note. Values are mean \pm standard deviation or number

${ }^{a}$ Quantitative data did not exhibit normal distribution and Mann-Whitney $U$ test was applied

$P<0.05$ indicates significant difference; Significant $P$ values are in bold

SN solid nodule, SSN Subsolid nodule, NIC Normalized iodine concentration, NWC Normalized water concentration, Slope $\lambda$ HU the slope of the spectral Hounsfield unit curve, Effective $Z$ effective atomic number 
deviations $(\mathrm{X} \pm \mathrm{S})$ for continuous variables and as frequency or percentage for categorical variables. The normality of continuous variables was analyzed using one-sample Kolmogorov-Smirnov Z tests (K-S tests). Univariate analyses were performed to assess the difference in clinical and DESCT characteristics between patients with KRAS mutations and patients with EGFR mutations. A t test was used if the continuous data exhibited a normal distribution; the Mann-Whitney $U$ test was used if the continuous data did not have a normal distribution. Categorical data were compared using chi-square $\left(\chi^{2}\right)$ tests or Fisher's exact tests. The significant factors in univariate analyses were identified as candidate covariates in logistic regression models with backward elimination of covariates, and the odds ratios (OR) were calculated. A receiver operating characteristic (ROC) curve was generated for KRAS mutation prediction according to each significant factor. Diagnostic capability was assessed by calculating the area under curve (AUC). $P$ values
$<0.05$ were considered significant. The statistical analyses were performed using SPSS 19.0 (SPSS Inc., Chicago, IL) statistical software package.

\section{Results}

A total of 72 patients with lung adenocarcinoma (30 males and 42 females; age $55.9 \pm 11.6$ years old) who underwent DESCT scanning and EGFR and KRAS testing were included in this study. According to the outcomes of gene testing, 60 patients had EGFR mutations (the EGFR group) and 12 patients exhibited KRAS mutations (the KRAS group).

Clinical and nodule type of patients with KRAS mutations compared to those with EGFR mutations in lung adenocarcinomas

Patient clinical and DESCT characteristics are reported in Table 1. KRAS mutations were less common in nonsmoking people than EGFR mutations (33.3\% vs $78.3 \%$ ).

Table 3 Comparison between clinical and DESCT characteristics with KRAS and EGFR mutation status in solid lung adenocarcinoma

\begin{tabular}{|c|c|c|c|c|}
\hline Characteristics & Total & KRAS & $E G F R$ & $P$ value \\
\hline No. of patients & 56 & 12 & 44 & \\
\hline Age $(y)^{a}$ & $55.98 \pm 10.37$ & $58.75 \pm 7.53$ & $55.23 \pm 10.97$ & 0.301 \\
\hline Sex & & & & 0.149 \\
\hline Female & $29(51.8)$ & $4(33.3)$ & $25(56.8)$ & \\
\hline Male & $27(48.2)$ & $8(66.7)$ & $19(43.2)$ & \\
\hline Smoking & & & & 0.012 \\
\hline Never smoked & $36(64.3)$ & $4(33.3)$ & $32(72.7)$ & \\
\hline Smoker & $20(35.7)$ & $8(66.7)$ & $12(27.3)$ & \\
\hline Location & & & & 0.452 \\
\hline Central & $2(3.6)$ & $0(0.0)$ & $2(4.5)$ & \\
\hline Peripheral & $54(96.4)$ & $12(100.0)$ & $42(95.5)$ & \\
\hline T stage & & & & 0.148 \\
\hline $\mathrm{T}_{1-2}$ & $52(92.9)$ & $10(83.3)$ & $42(95.5)$ & \\
\hline $\mathrm{T}_{3-4}$ & $4(7.1)$ & $2(16.7)$ & $2(4.5)$ & \\
\hline N stage & & & & 0.158 \\
\hline $\mathrm{N}_{0}$ & $32(57.1)$ & $9(7.5)$ & $23(52.3)$ & \\
\hline $\mathrm{N}_{1-2}$ & $24(42.9)$ & $3(2.5)$ & $21(47.7)$ & \\
\hline Maximum diameter ${ }^{b}$ & $3.15 \pm 1.32$ & $3.17 \pm 1.38$ & $3.14 \pm 1.32$ & 0.742 \\
\hline \multicolumn{5}{|c|}{ DESCT quantitative parameter } \\
\hline $\mathrm{CT}$ number at $70 \mathrm{keV}^{\mathrm{a}}$ & $47.39 \pm 23.04$ & $31.52 \pm 22.26$ & $51.71 \pm 21.51$ & 0.006 \\
\hline Slope $\lambda H U^{b}$ & $1.71 \pm 0.92$ & $1.17 \pm 0.77$ & $1.85 \pm 0.91$ & 0.017 \\
\hline$N I C^{b}$ & $0.198 \pm 0.12$ & $0.14 \pm 0.09$ & $0.21 \pm 0.12$ & 0.013 \\
\hline$N W C^{b}$ & $0.989 \pm 0.02$ & $0.98 \pm 0.02$ & $0.99 \pm 0.02$ & 0.239 \\
\hline Effective $Z^{a}$ & $8.45 \pm 0.43$ & $8.17 \pm 0.39$ & $8.52 \pm 0.41$ & 0.010 \\
\hline
\end{tabular}

Note. Values are mean \pm standard deviation or number (percentage)

${ }^{a}$ Quantitative data exhibited normal distribution and T test was applied

${ }^{\mathrm{b}}$ Quantitative data did not exhibit normal distribution and Mann-Whitney $U$ test was applied

$P<0.05$ indicates significant difference; Significant $P$ values are in bold

NIC Normalized iodine concentration, NWC Normalized water concentration, Slope $\lambda H U$ the slope of the spectral Hounsfield unit curve, Effective Z effective atomic number 


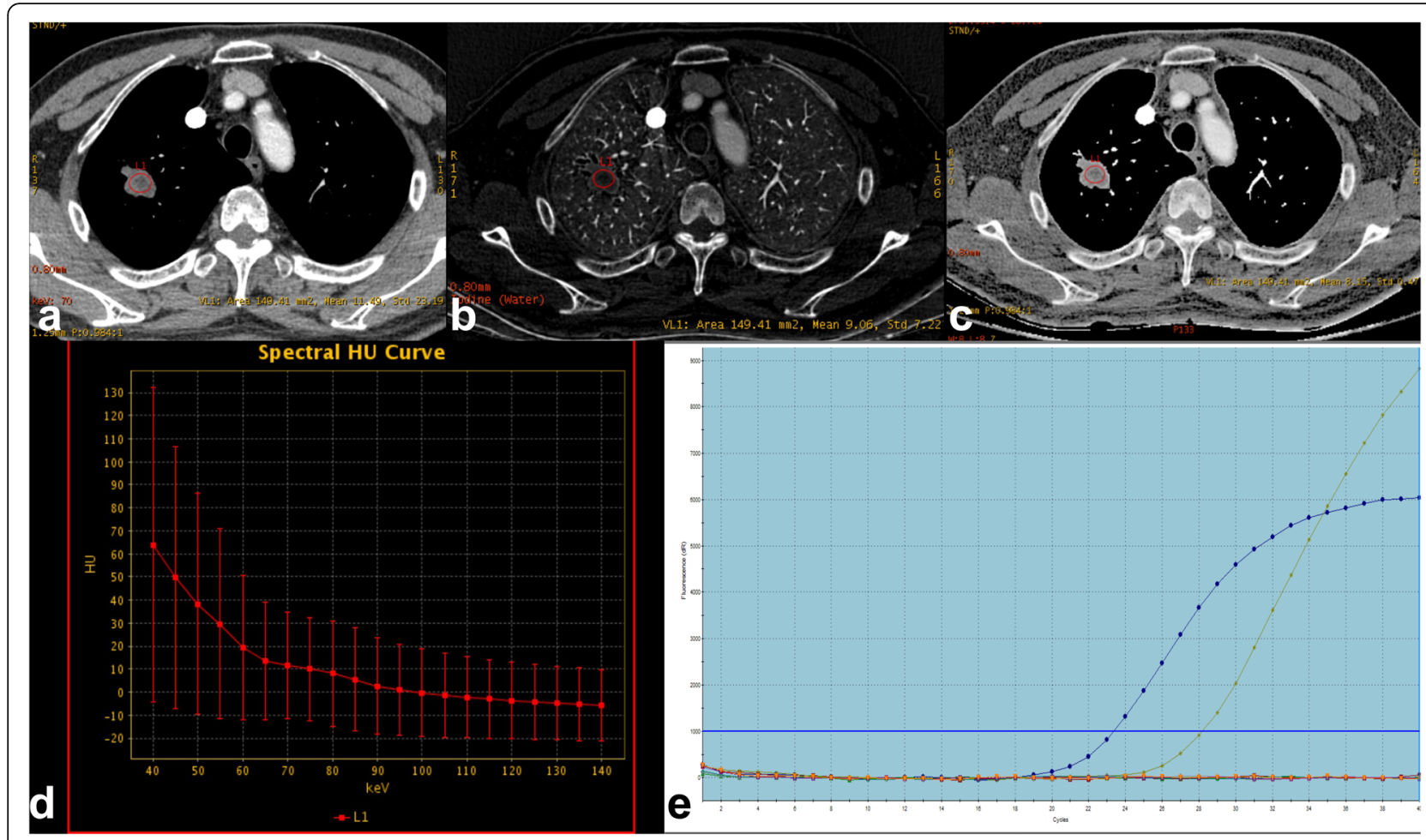

Fig. 2 Male, 73 years old, lung adenocarcinoma with KRAS mutation. (a) A DESCT $70 \mathrm{keV}$ image showed a solid nodule in the middle lobe of the right lung; the CT number at $70 \mathrm{keV}$ was $11.49 \mathrm{Hu}$. (b) An iodine-based material-decomposition image reveals that the iodine concentration (IC) of the nodule is $9.06 \mu \mathrm{g} / \mathrm{cm} 3(\mathrm{~L} 1)$. The IC of the aorta is $77.24 \mu \mathrm{g} / \mathrm{cm} 3$. The normalized IC (NIC) of this lung adenocarcinoma is $0.12(9.06 / 77.24)$. (c) The effective $Z$ material-decomposition image shows that the effective $Z$ of the nodule is 8.15. (d) The graph shows the spectral HU curve of the nodule. Slope $\lambda H U$ is 1.01. (e) The molecular pathological results showed KRAS mutations

Nodule type was significantly different between the two mutations $(P=0.035)$, and all KRAS mutation adenocarcinomas were $\mathrm{SN}$ tumors.

\section{Influence of nodule type on the quantitative parameters from DESCT}

The mean values of the CT number at $70 \mathrm{keV}$, slope $\lambda \mathrm{HU}$, $\mathrm{NIC}, \mathrm{NWC}$, and effective $\mathrm{Z}$ were significantly different in SN tumors compared to SSN tumors, as shown in Table 2. There was no statistically significant difference in the effective $\mathrm{Z}$ between $\mathrm{SN}$ and SSN tumors, although the mean value in SSN was lower than that in SN (6.69 vs. 8.45).

\section{Clinical and quantitative DESCT parameters of patients with KRAS mutations compared to those with EGFR mutations in solid lung adenocarcinoma}

Because nodule type has obviously impact on DESCT quantitative parameters and all KRAS mutation adenocarcinomas were SN tumors, to make the measurement comparable, we deleted imaging data of the EGFR mutation group with SSN tumors before comparing differences between the two groups $(n=12$ to $n=44)$. The clinical and DESCT characteristics of solid lung adenocarcinoma are reported in Table 3. For DESCT quantitative parameters, the $\mathrm{CT}$ number at $70 \mathrm{keV}$, slope $\lambda$ HU, NIC, and effective $Z$ values differed significantly between the KRAS and EGFR groups $(P=0.006,0.017$, 0.013 and 0.010 , respectively) (Figs. 2, 3).

Multivariate analyses evaluating smoking, sex, CT number at $70 \mathrm{keV}$, NIC, effective Z, and slope $\lambda$ HU showed that smoking $(\mathrm{OR}=7.421, P=0.016)$ and $\mathrm{CT}$ number at $70 \mathrm{keV}(\mathrm{OR}=0.938, P=0.009)$ were two independent prognostic factors for $K R A S$ mutations compared to EGFR mutations in solid lung adenocarcinoma (Table 4). The AUC of CT number at $70 \mathrm{keV}$ is 0.771 (95\% CI: $0.597-$ $0.945, P=0.004$ ) with the cutoff point of $38.47 \mathrm{HU}$. Based on this multivariate analysis, the two significant factors (CT number at $70 \mathrm{keV}$ and smoking history) were combined to determine the predictive value to differentiate KRAS and EGFR mutations. The AUC of combining the two factors was 0.841 (95\% CI: $0.717-0.965, P<0.001$ ) with the cutoff point of 2.72 (Fig. 4).

\section{Discussion}

Few studies have investigated conventional CT features and KRAS mutations in lung adenocarcinoma. Previous studies by Glynn et al. [15] did not find any conventional CT characteristics associated with KRAS mutations in 


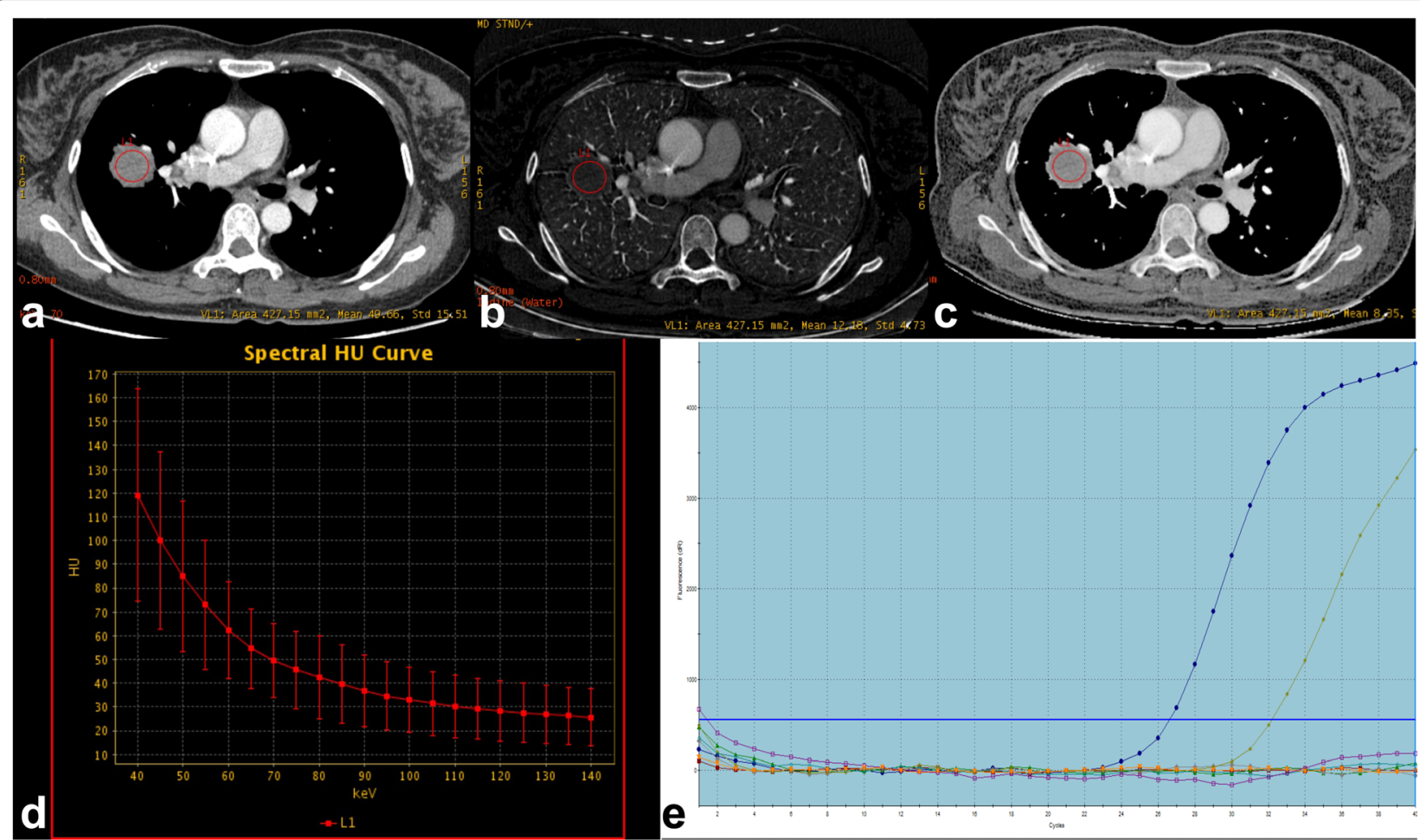

Fig. 3 Female, 39 years old, lung adenocarcinoma with EGFR mutation. (a) A DESCT $70 \mathrm{keV}$ image showed a solid nodule in the inferior lobe of the left lung. The CT number at $70 \mathrm{keV}$ was $49.66 \mathrm{HU}$. (b) An iodine-based material-decomposition image shows that the iodine concentration (IC) of the nodule is $12.18 \mu \mathrm{g} / \mathrm{cm} 3$; the IC of the aorta is $76.23 \mu \mathrm{g} / \mathrm{cm} 3$; the normalized IC (NIC) of this lung adenocarcinoma is 0.16 (12.18/76.23). (c) The effective $Z$ material-decomposition image shows that the effective $Z$ of the nodule is 8.35. (d) The graph shows the spectral HU curve of the nodule; slope $\lambda \mathrm{HU}$ is 0.82. (e) The molecular pathological results showed EGFR mutations

patients with lung adenocarcinoma. Although some other studies showed that size, spiculation sign, and air bronchogram sign may be related to KRAS mutations, the results were quite inconsistent [16-18]. These negative or inconsistent results may reflect the limitations of conventional CT imaging signs, which lack a quantitative index and are unstable due to subjective judgment. In contrast, it is now widely recognized that the GGO ratio is significantly higher in tumors with EGFR mutations [13, 35, 36]. This phenomenon may be because EGFR mutations appear more frequently in lepidic predominant adenocarcinomas, which are associated with better outcomes [35, 37]. In this study, the SSN rate in tumors with EGFR mutations was

Table 4 Multivariable Analysis of DESCT and Clinical Features Predicting the Presence of KRAS Mutation Compared to EGFR Mutation in Solid Lung Adenocarcinoma

\begin{tabular}{lllc}
\hline Characteristics & OR & $95 \% \mathrm{Cl}$ & $P$ value \\
\hline Smoking & & & 0.016 \\
Never smoked & Reference & NA & \\
Smoker & 7.421 & $1.451-37.948$ & \\
CT number at 70 keV & 0.938 & $0.894-0.984$ & 0.009 \\
\hline
\end{tabular}

Note. NA not applicable. OR odd ratio. $\mathrm{Cl}$ confidence interval higher than that in KRAS mutations ( $26.7 \%$ vs. $0 \%)$, and all KRAS mutation tumors were solid.

Given the difference in SSN that was observed between the KRAS and EGFR groups, we also studied the relationship between nodule type and DESCT quantitative parameters, which also has scarce been reported previously. Our results showed that all DESCT quantitative parameters, except effective Z, differed between SSN tumors and SN tumors. Effective Z was lower in SSN than $\mathrm{SN}$, and although no statistically significant difference was observed, more sample size research is needed. The SSN contains an extremely low air attenuation, which result in low $\mathrm{CT}$ number at $70 \mathrm{keV}$. It is worthwhile to note that NIC and Slope $\lambda$ HU of SSN were higher than $\mathrm{SN}$ on the contrary. This results suggest that NIC and Slope $\lambda \mathrm{HU}$ can hardly be affected by the low air attenuation in SSN, and the reason maybe the relatively small size and rich blood vessels or volume in the early stage tumor [38].

To eliminate the impact of SSN on DESCT quantitative parameters, and since the KRAS mutation adenocarcinoma are all SN as well, we deleted imaging data of SSN and then compared the difference between the two groups (KRAS $n=12$ to EGFR $n=44$ ). The results 


\section{ROC curves}

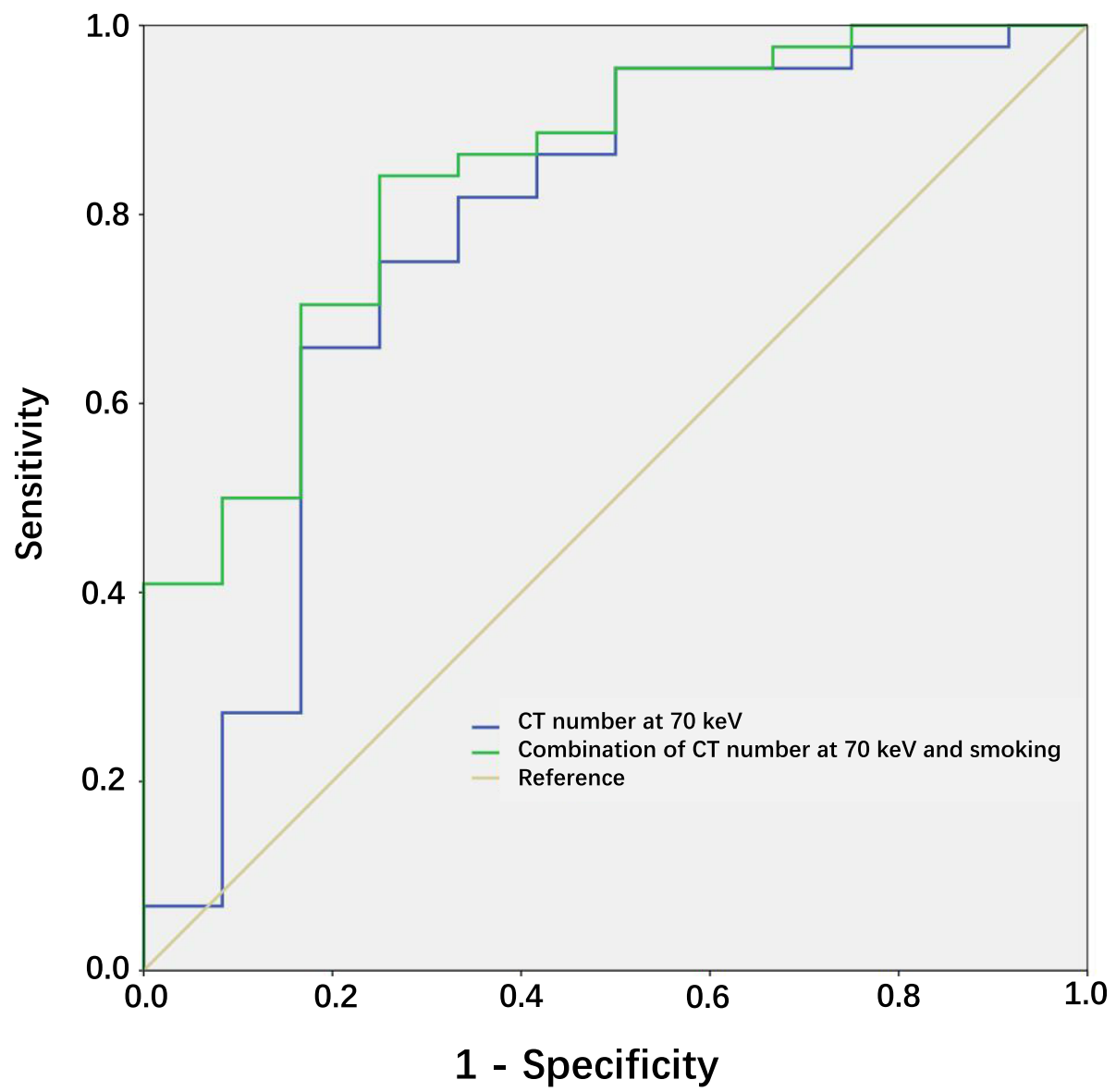

Fig. 4 Graph shows the receiver operating characteristic (ROC) curve for discrimination of patients with KRAS mutations from those with EGFR mutations at DESCT (CT number at $70 \mathrm{keV}$ ) including and not including smoking in solid lung adenocarcinoma. The area under Curve (AUC) of CT number at $70 \mathrm{keV}$ is 0.771 with the cutoff point of $38.47 \mathrm{HU}$. The AUC of combination of CT number at $70 \mathrm{keV}$ and smoking is 0.841 with the cutoff point of 2.72

showed that the CT number at $70 \mathrm{keV}$, slope $\lambda \mathrm{HU}$, $\mathrm{NIC}$, and effective $\mathrm{Z}$ were significantly different between solid lung adenocarcinomas with KRAS and EGFR mutations. KRAS mutations in lung adenocarcinoma have special pathological features. In terms of the histological type, KRAS mutations are associated more with mucinous adenocarcinoma or lung cancer with goblet cell morphology than with nonmucinous adenocarcinoma [39-42]. On the other hand, studies have shown that in addition to cancer genesis and development, EGFR also plays important roles in stimulating angiogenesis through very complicated biological processes [43, 44]. We speculate that the DESCT findings might correlate with the underlying pathologic appearance. The mucus produced in KRAS mutation lung adenocarcinoma and the rich blood supply of EGFR mutation lung adenocarcinoma may result in the lower quantitative value with KRAS mutations compared to EGFR mutations.
A relationship between KRAS mutational status and lung CT image features could improve the accuracy of medical decisions. Multivariate logistic analysis combining clinical and DESCT characteristics showed that CT value at $70 \mathrm{keV}$ and smoking were the two independent factors potentially able to predict the presence of KRAS mutations from EGFR mutations in solid lung adenocarcinomas. The combination of CT number at $70 \mathrm{keV}$ with smoking history was a powerful tool to differentiate KRAS and EGFR mutations, which could be used to aid in clinical diagnosis in the future. The ROC obtained by combining these significant factors also showed a relatively high predictive value for identifying KRAS mutations (AUC = 0.841, 95\% CI: 0.717-0.965). This finding suggests that combining clinical and DESCT characteristics can be recommended for use to differentiate KRAS and EGFR status in solid lung adenocarcinomas. 
The prevalence of KRAS mutations is much lower in East Asian patients than in Western patients $(8.3 \%$ vs. $32 \%$, respectively) $[45,46]$. Our study showed a KRAS mutation prevalence of $11.3 \%(12 / 106)$ in this population. In a previous study, KRAS mutations were more frequent in smokers and male patients than EGFR mutations [47]. In the same study, smoking history was found to be a significant determinant, while gender was a confounding factor [47]. In this study's analysis of clinical characteristics, smoking history was significant factor in both univariate and multivariate analyses, which is consistent with previous work. The KRAS mutation was also more frequent in males than the EGFR mutation, but this gender difference was not significant $(P=0.054)$.

Although histological and immunohistochemical analyses have been accepted as the reference standard, identification of the relationship between DESCT quantitative measurements and KRAS status could help determine the molecular categories of lung adenocarcinoma. First, histological and immunohistochemical analyses of biopsies or surgical specimens is an invasive method, and it has also been well documented that diagnostic errors are common $[48,49]$. Hence, additional diagnostic information can help improve accuracy. Second, compared with molecular technologies, routine imaging can provide a more comprehensive view of the entire tumor and can be used on an ongoing basis to monitor relapse after surgery much less invasively. This benefit is even more critical in larger tumors, which can exhibit intratumor genomic heterogeneity [50]. Third, the relationship may suggest a greater need for blinded targeted therapies for the patients who cannot undergo histological sampling.

This study is the first to describe the imaging differences between lung cancer patients with KRAS and EGFR mutations using DESCT according to our knowledge. The present study also has several limitations. First, the retrospective single-center design has various potential biases. Second, the enrolled sample size was relatively small, especially for patients with KRAS mutations. Therefore, studies should be conducted with larger sample sizes to examine the precise characteristics of these mutations in the future.

\section{Conclusions}

In conclusion, the $\mathrm{SN}$ proportion was higher with $K R A S$ than EGFR mutations and all KRAS mutation adenocarcinomas were SN tumors. DESCT features, especially CT number at $70 \mathrm{keV}$, can be an image biomarker to help distinguish KRAS and EGFR mutations in solid lung adenocarcinoma. Combining DESCT-based features with clinical variables - such as CT value at $70 \mathrm{keV}$ with smoking history - is a promising approach for improving the discrimination of KRAS mutations from EGFR mutations in solid lung adenocarcinoma.

\section{Abbreviations}

DESCT: Dual-energy spectral computed tomography; Effective Z: Effective atomic number; EGFR: Epidermal growth factor receptor; FISH: Fluorescence in situ hybridization; GGO: Ground-glass opacity; GSI: Gemstone spectral imaging; IHC: Immunohistochemistry; KRAS: Kirsten rat sarcoma viral oncogene homolog; NIC: Normalized iodine concentration; NSN: Nonsolid nodule; NWC: Normalized water concentration; Slope $\lambda \mathrm{HU}$ : Slope of the spectral Hounsfield unit curve; SN: Solid nodule; SSN: Subsolid nodule

\section{Acknowledgements}

We thank Tian Qiu MD for molecular pathological technical assistance, Ling-Ling Wang PhD and Jin Guo PhD for technical assistance in performing DESCT examinations.

\section{Authors' contributions}

$\mathrm{ML}$ and NW conceived and designed the study. WT, Y-JJ and L-LQ contributed data collection. $\mathrm{ML}$ and $\mathrm{LZ}$ contributed to data interpretation and statistical analysis. ML and J-CD prepared the manuscript. NW revised the manuscript. All authors read and approved the final manuscript.

\section{Funding}

This study was supported by the National Natural Science Foundation of China (No. 81601494) and the Fundamental Research Funds for the Central Universities (No. 3332018196). The funding source had no involvement in study design, interpretation of data and writing of the article.

\section{Availability of data and materials}

The datasets used and/or analyzed during the current study are available from the corresponding author on reasonable request.

\section{Ethics approval and consent to participate}

The study was approved by the Ethics Committee of Cancer Hospital, Chinese Academy of Medical Sciences (NCC2016G-029).

\section{Consent for publication}

All the authors have consented to the publication of this manuscript.

\section{Competing interests}

The authors declare that they have no competing interests.

\section{Author details}

'Department of Diagnostic Radiology, National Cancer Center/National Clinical Research Center for Cancer/Cancer Hospital, Chinese Academy of Medical Sciences and Peking Union Medical College, Beijing, 100021, China. ${ }^{2}$ Department of Medical Oncology, National Cancer Center/National Clinical Research Center for Cancer/Cancer Hospital, Chinese Academy of Medical Sciences and Peking Union Medical College, Beijing, 100021, China. ${ }^{3}$ PET-CT Center, National Cancer Center/National Clinical Research Center for Cancer/ Cancer Hospital, Chinese Academy of Medical Sciences and Peking Union Medical College, Beijing, 100021, China.

Received: 11 October 2018 Accepted: 6 November 2019

Published online: 29 November 2019

References

1. Bray F, Ferlay J, Soerjomataram I, Siegel RL, Torre LA, Jemal A. Global cancer statistics 2018: GLOBOCAN estimates of incidence and mortality worldwide for 36 cancers in 185 countries. CA Cancer J Clin. 2018.

2. Zhang L, Li M, Wu N, Chen Y. Time trends in epidemiologic characteristics and imaging features of lung adenocarcinoma: a population study of 21,113 cases in China. PLoS One. 2015;10(8):e0136727.

3. Travis WD. Reporting lung cancer pathology specimens. Impact of the anticipated 7th edition TNM classification based on recommendations of the IASLC staging committee. Histopathology. 2009;54(1):3-11.

4. Lynch TJ, Bell DW, Sordella R, Gurubhagavatula S, Okimoto RA, Brannigan BW, Harris PL, Haserlat SM, Supko JG, Haluska FG, et al. Activating mutations in the epidermal growth factor receptor underlying responsiveness of nonsmall-cell lung cancer to gefitinib. N Engl J Med. 2004;350(21):2129-39.

5. Paez JG, Janne PA, Lee JC, Tracy S, Greulich H, Gabriel S, Herman P, Kaye FJ, Lindeman N, Boggon TJ, et al. EGFR mutations in lung cancer: correlation with clinical response to gefitinib therapy. Science. 2004;304(5676):1497-500. 
6. Gerber DE, Gandhi L, Costa DB. Management and future directions in nonsmall cell lung cancer with known activating mutations. Am Soc Clin Oncol Educ Book. 2014:e353-65.

7. Meng D, Yuan M, Li X, Chen L, Yang J, Zhao X, Ma W, Xin J. Prognostic value of K-RAS mutations in patients with non-small cell lung cancer: a systematic review with meta-analysis. Lung Cancer. 2013;81(1):1-10.

8. Woo T, Okudela K, Yazawa T, Wada N, Ogawa N, Ishiwa N, Tajiri M, Rino Y, Kitamura H, Masuda M. Prognostic value of KRAS mutations and Ki-67 expression in stage I lung adenocarcinomas. Lung Cancer. 2009;65(3):355-62.

9. Kim YT, Kim TY, Lee DS, Park SJ, Park JY, Seo SJ, Choi HS, Kang HJ, Hahn S, Kang $\mathrm{CH}$, et al. Molecular changes of epidermal growth factor receptor (EGFR) and KRAS and their impact on the clinical outcomes in surgically resected adenocarcinoma of the lung. Lung Cancer. 2008;59(1):111-8.

10. Huncharek M, Muscat J, Geschwind JF. K-ras oncogene mutation as a prognostic marker in non-small cell lung cancer: a combined analysis of 881 cases. Carcinogenesis. 1999;20(8):1507-10

11. Grossi F, Loprevite M, Chiaramondia M, Ceppa P, Pera C, Ratto GB, Serrano J, Ferrara GB, Costa R, Boni L, et al. Prognostic significance of K-ras, p53, bcl-2, PCNA, CD34 in radically resected non-small cell lung cancers. Eur J Cancer. 2003;39(9):1242-50.

12. Lindeman $\mathrm{NI}$, Cagle PT, Aisner DL, Arcila ME, Beasley MB, Bernicker $\mathrm{E}$, Colasacco C, Dacic S, Hirsch FR, Kerr K, et al. Updated molecular testing guideline for the selection of lung Cancer patients for treatment with targeted tyrosine kinase inhibitors: guideline from the College of American Pathologists, the International Association for the Study of Lung Cancer, and the Association for Molecular Pathology. Arch Pathol Lab Med. 2018.

13. Liu Y, Kim J, Qu F, Liu S, Wang H, Balagurunathan Y, Ye Z, Gillies RJ. CT features associated with epidermal growth factor receptor mutation status in patients with lung adenocarcinoma. Radiology. 2016;280(1):271-80.

14. Cheng Z, Shan F, Yang Y, Shi Y, Zhang Z. CT characteristics of non-small cell lung cancer with epidermal growth factor receptor mutation: a systematic review and meta-analysis. BMC Med Imaging. 2017;17(1):5.

15. Glynn C, Zakowski MF, Ginsberg MS. Are there imaging characteristics associated with epidermal growth factor receptor and KRAS mutations in patients with adenocarcinoma of the lung with bronchioloalveolar features? J Thorac Oncol. 2010;5(3):344-8.

16. Wang H, Schabath MB, Liu Y, Stringfield O, Balagurunathan $Y$, Heine JJ, Eschrich SA, Ye Z, Gillies RJ. Association between computed tomographic features and Kirsten rat sarcoma viral oncogene mutations in patients with stage I lung adenocarcinoma and their prognostic value. Clin Lung Cancer. 2016;17(4):271-8.

17. Sugano M, Shimizu K, Nakano T, Kakegawa S, Miyamae Y, Kaira K, Araki T, Kamiyoshihara M, Kawashima O, Takeyoshi I. Correlation between computed tomography findings and epidermal growth factor receptor and KRAS gene mutations in patients with pulmonary adenocarcinoma. Oncol Rep. 2011; 26(5):1205-11

18. Gevaert O, Xu J, Hoang CD, Leung AN, Xu Y, Quon A, Rubin DL, Napel S, Plevritis SK. Non-small cell lung cancer: identifying prognostic imaging biomarkers by leveraging public gene expression microarray data--methods and preliminary results. Radiology. 2012;264(2):387-96.

19. Johnson TR, Krauss B, Sedlmair M, Grasruck M, Bruder H, Morhard D, Fink C, Weckbach S, Lenhard M, Schmidt B, et al. Material differentiation by dual energy CT: initial experience. Eur Radiol. 2007;17(6):1510-7.

20. Goo HW, Goo JM. Dual-energy CT: new horizon in medical imaging. Korean J Radiol. 2017;18(4):555-69.

21. Matsuda I, Akahane M, Sato J, Katsura M, Kiryu S, Yoshioka N, Kunimatsu A, Ino K, Ohtomo K. Precision of the measurement of CT numbers: comparison of dual-energy CT spectral imaging with fast kVp switching and conventional CT with phantoms. Jpn J Radiol. 2012;30(1):34-9.

22. Patino M, Prochowski A, Agrawal MD, Simeone FJ, Gupta R, Hahn PF, Sahani DV. Material separation using dual-energy CT: current and emerging applications. Radiographics. 2016;36(4):1087-105.

23. Simons D, Kachelriess M, Schlemmer HP. Recent developments of dualenergy CT in oncology. Eur Radiol. 2014;24(4):930-9.

24. De Cecco CN, Darnell A, Rengo M, Muscogiuri G, Bellini D, Ayuso C, Laghi A Dual-energy CT: oncologic applications. AJR Am J Roentgenol. 2012;199(5 Suppl):S98-S105

25. Gonzalez-Perez V, Arana E, Barrios M, Bartres A, Cruz J, Montero R, Gonzalez M, Deltoro C, Martinez-Perez E, De Aguiar-Quevedo K, et al. Differentiation of benign and malignant lung lesions: dual-energy computed tomography findings. Eur J Radiol. 2016;85(10):1765-72.
26. Wang G, Zhang C, Li M, Deng K, Li W. Preliminary application of highdefinition computed tomographic gemstone spectral imaging in lung cancer. J Comput Assist Tomogr. 2014;38(1):77-81.

27. Hou WS, Wu HW, Yin Y, Cheng JJ, Zhang Q, Xu JR. Differentiation of lung cancers from inflammatory masses with dual-energy spectral CT imaging. Acad Radiol. 2015;22(3):337-44

28. Otrakji A, Digumarthy SR, Lo Gullo R, Flores EJ, Shepard JA, Kalra MK. Dual-energy CT: Spectrum of thoracic abnormalities. Radiographics. 2016;36(1):38-52.

29. Chae EJ, Song JW, Seo JB, Krauss B, Jang YM, Song KS. Clinical utility of dual-energy $C T$ in the evaluation of solitary pulmonary nodules: initial experience. Radiology. 2008;249(2):671-81.

30. Remy-Jardin M, Faivre JB, Pontana F, Molinari F, Tacelli N, Remy J. Thoracic applications of dual energy. Semin Respir Crit Care Med. 2014;35(1):64-73.

31. Ohana M, Jeung MY, Labani A, El Ghannudi S, Roy C. Thoracic dual energy CT: acquisition protocols, current applications and future developments. Diagn Interv Imaging. 2014;95(11):1017-26.

32. Hansell DM, Bankier AA, MacMahon H, McLoud TC, Muller NL, Remy J. Fleischner society: glossary of terms for thoracic imaging. Radiology. 2008; 246(3):697-722.

33. Godoy MC, Naidich DP. Subsolid pulmonary nodules and the spectrum of peripheral adenocarcinomas of the lung: recommended interim guidelines for assessment and management. Radiology. 2009;253(3):606-22.

34. Truong MT, Ko JP, Rossi SE, Rossi I, Viswanathan C, Bruzzi JF, Marom EM Erasmus JJ. Update in the evaluation of the solitary pulmonary nodule. Radiographics. 2014;34(6):1658-79.

35. Lee HJ, Kim YT, Kang CH, Zhao B, Tan Y, Schwartz LH, Persigehl T, Jeon YK, Chung $\mathrm{DH}$. Epidermal growth factor receptor mutation in lung adenocarcinomas: relationship with CT characteristics and histologic subtypes. Radiology. 2013;268(1):254-64.

36. Yang $Y$, Yang $Y$, Zhou X, Song $X$, Liu M, He W, Wang H, Wu C, Fei K, Jiang G. EGFR L858R mutation is associated with lung adenocarcinoma patients with dominant ground-glass opacity. Lung Cancer. 2015;87(3):272-7.

37. Travis WD, Brambilla E, Noguchi M, Nicholson AG, Geisinger KR, Yatabe $Y$, Beer DG, Powell CA, Riely GJ, Van Schil PE, et al. International association for the study of lung cancer/american thoracic society/european respiratory society international multidisciplinary classification of lung adenocarcinoma. J Thorac Oncol. 2011;6(2):244-85.

38. Aoki M, Takai $Y$, Narita $Y$, Hirose $K$, Sato M, Akimoto $H$, Kawaguchi $H$, Hatayama $Y$, Miura H, Ono S. Correlation between tumor size and blood volume in lung tumors: a prospective study on dual-energy gemstone spectral CT imaging. J Radiat Res. 2014;55(5):917-23.

39. Suda K, Tomizawa K, Mitsudomi T. Biological and clinical significance of KRAS mutations in lung cancer: an oncogenic driver that contrasts with EGFR mutation. Cancer Metastasis Rev. 2010;29(1):49-60.

40. Hata A, Katakami N, Fujita S, Kaji R, Imai Y, Takahashi Y, Nishimura T, Tomii K, Ishihara K. Frequency of EGFR and KRAS mutations in Japanese patients with lung adenocarcinoma with features of the mucinous subtype of bronchioloalveolar carcinoma. J Thorac Oncol. 2010;5(8):1197-200.

41. Marchetti A, Buttitta F, Pellegrini S, Chella A, Bertacca G, Filardo A, Tognoni $V$, Ferreli F, Signorini E, Angeletti CA, et al. Bronchioloalveolar lung carcinomas: K-ras mutations are constant events in the mucinous subtype. Pathol. 1996;179(3):254-9.

42. Finberg KE, Sequist LV, Joshi VA, Muzikansky A, Miller JM, Han M, Beheshti J, Chirieac LR, Mark EJ, lafrate AJ. Mucinous differentiation correlates with absence of EGFR mutation and presence of KRAS mutation in lung adenocarcinomas with bronchioloalveolar features. J Mol Diagn. 2007;9(3):320-6.

43. Manning BD, Cantley LC. AKT/PKB signaling: navigating downstream. Cell. 2007;129(7):1261-74

44. Gordan JD, Simon MC. Hypoxia-inducible factors: central regulators of the tumor phenotype. Curr Opin Genet Dev. 2007;17(1):71-7.

45. Zheng D, Wang R, Zhang Y, Pan Y, Cheng X, Cheng C, Zheng S, Li H, Gong $R$, Li $Y$, et al. The prevalence and prognostic significance of KRAS mutation subtypes in lung adenocarcinomas from Chinese populations. Onco Targets Ther. 2016:9:833-43.

46. Cancer Genome Atlas Research N. Comprehensive molecular profiling of lung adenocarcinoma. Nature. 2014;511(7511):543-50.

47. Tam IY, Chung LP, Suen WS, Wang E, Wong MC, Ho KK, Lam WK, Chiu SW, Girard L, Minna JD, et al. Distinct epidermal growth factor receptor and KRAS mutation patterns in non-small cell lung cancer patients with different tobacco exposure and clinicopathologic features. Clin Cancer Res. 2006; 12(5):1647-53. 
48. Graber ML: The incidence of diagnostic error in medicine. BMJ Qual Saf 2013, 22 Suppl 2:ii21-2:ii27.

49. Querings S, Altmuller J, Ansen S, Zander T, Seidel D, Gabler F, Peifer M, Markert E, Stemshorn K, Timmermann B, et al. Benchmarking of mutation diagnostics in clinical lung cancer specimens. PLoS One. 2011;6(5):e19601.

50. Yap TA, Gerlinger M, Futreal PA, Pusztai L, Swanton C. Intratumor heterogeneity: seeing the wood for the trees. Sci Transl Med. 2012;4(127):127ps110.

\section{Publisher's Note}

Springer Nature remains neutral with regard to jurisdictional claims in published maps and institutional affiliations.

Ready to submit your research? Choose BMC and benefit from:

- fast, convenient online submission

- thorough peer review by experienced researchers in your field

- rapid publication on acceptance

- support for research data, including large and complex data types

- gold Open Access which fosters wider collaboration and increased citations

- maximum visibility for your research: over $100 \mathrm{M}$ website views per year

At $\mathrm{BMC}$, research is always in progress.

Learn more biomedcentral.com/submissions 